International Journal of Instruction e-ISSN: 1308-1470 • www.e-iji.net
July $2019 \bullet$ Vol.12, No.3

p-ISSN: 1694-609X

pp. 651-664

Received: 10/11/2018

Revision: 22/04/2019

Accepted: 26/04/2019

OnlineFirst:15/05/2019

\title{
Developing Vignettes to Assess Mathematical Knowledge for Teaching based Conceptual
}

\section{Latief Sahidin}

Mathematics Education Universitas Halu Oleo, Indonesia, latief.sahidin@uho.ac.id

\section{Mega Teguh Budiarto}

Mathematics Education State University of Surabaya, Indonesia, megatbudiarto@unesa.ac.id

\section{Yusuf Fuad}

Mathematics Education State University of Surabaya, Indonesia,yusuffuad@unesa.ac.id

The objective of this study is to produce a vignette in measuring mathematical knowledge for teaching based conceptual (MKT-C). The method of this research is a development research conducted by synthesizing the expert reviews on MKT-C in the knowledge domain of material content which was divided into sub domains: common content knowledge based conceptual (CCK-C), specialized content knowledge based conceptual (SCK-C) and knowledge at the mathematical horizon based conceptual (KMH-C) through vignette. The research procedure is as follows: defining constructs, identifying and preparing indicators, developing vignette, validating experts or expert validation and trial test. The research phases included (1) preliminary phase: preparation and design and (2) formative evaluation phase: self-evaluation, prototyping and field test (Tessmer, 2013). At formative evaluation phase, self-evaluation began and it is done by the researcher himself. In expert review phase, validation in terms of content, construct and language by experts was done. One-to-one phase was conducted for the teacher to test the readability. Then it was tried out to the teachers in the small group of non-research subjects. They were asked for suggestions and comments for improvement. The small group carried out was to 29 teachers who participated in the teacher professional education program at Universitas Halu Oleo.

Keywords: mathematical knowledge, teaching based conceptual, vignettes, mathematics education, measuring mathematical knowledge 


\section{INTRODUCTION}

Learning mathematics is determined by the teacher factor. Teachers as determinants of student learning achievement in learning mathematics are influenced by various factors, one of which is the teacher's knowledge factor. Teacher's knowledge is determined from two aspects, namely content mastery about topics to be taught and learning strategies (Chick, 2003). A teacher cannot be expected to explain mathematical concepts if he/she does not have a complete understanding of the mathematical concepts taught (Thames, 2006; Yeo, 2008). However, mastering the material to be taught is not enough to achieve the goals that the students want. On the other hand, teachers who lack knowledge tend to emphasize facts, rules (formulas), and procedures (Isiskal \& Cakiroglu, 2011).

Teachers who are expected to be able to teach effectively are teachers who not only master the material to be taught but are also able to explain using a variety of ways so that students easily understand it. For this reason, teachers need knowledge that can be used to transform the content knowledge (subject matter) that they already have into representation or presentation that can help students to develop their knowledge.

Researches on developing teacher knowledge, testing various pedagogical frameworks for understanding teacher knowledge (Ball, Lubienski \& Mewborn, 2001; Lappan, 2000; Fennema \& Frankie, 1992; An, Kulm \& Wu, 2004; Kim (2004); Türnüklü \& Yesildere, 2007) have been done. Based on the results of the studies, models of mathematical knowledge for teaching (MKT) can be grouped into two domains, namely: subject matter knowledge (SMK) and pedagogical content knowledge (PCK). SMK consists of common content knowledge (CCK), specialized content knowledge (SCK) and KMH. Whereas PCK includes: knowledge of content and students (KCS), knowledge of content and teaching (KCT), knowledge of content and curriculum (KCC).

Of the six MKT domains, CCK, SCK and KMH are the key domains of knowledge types that are important for teachers. The reason is teachers must have content knowledge including knowledge about the topic and organizational structure (Ball et al, 2008); teachers who do not have the knowledge and belief will experience difficulties in helping students achieve learning goals; teachers must understand the principles of organization and mathematical structures and rules. In other words, mathematics teachers must have conceptual knowledge, not only understand that something is like that; but the teacher must better understand why, on what basis, and under what circumstances the teacher's belief can justify something that is accepted or rejected. Thus, good mathematics teachers must have mathematical knowledge for teaching based conceptual (MKT-C) to become an effective teacher.

Some findings of preliminary study on teacher content knowledge on quadrilaterals in Kendari City are still experiencing difficulties (Sahidin, et al., 2018). Furthermore, research focusing specifically on the development of MKT assessment tools is not yet available in the literature. How is the construction of an assessment tool to measure the 
teacher's right MKT? The question is very important to be answered through research. Therefore, vignette as a form of test developments is used to construct a teacher's MKT$\mathrm{C}$ assessment tool. Vignette is a written form of material that is fictitious, containing background, references or information on observation results made consistently. Vignette contains a short scenario about real concepts that are possible or common in the field. The scenario is used as the main question then it is accompanied by a statement in the form of a short question based on the conditions or concepts contained in the scenario (Poulou, 2001).

\section{REVIEW OF LITERATURE}

\section{Mathematical Knowledge for Teaching (MKT) and Conceptual Knowledge}

Experts who developed theory of mathematical knowledge for teaching (MKT) were initiated by Shulman (Ball et al., 2008). At present, MKT is a very popular and prominent term in mathematics learning. MKT is the mathematical knowledge and skill used to teach (Ball et al., 2008; Nolan et al., 2015). The explanation shows that teaching mathematics requires mathematical knowledge that is special and different from other work which using mathematics as well. Teachers who teach mathematics need MKT to explain the concepts and definitions that are appropriate and understandable to students, ask good questions, plan teaching activities, give examples of mathematical ideas and relate them to other mathematical ideas, assess textbooks, choose teaching materials and evaluate learning.

The material content knowledge domain MKT includes three sub domains, namely: (1) common content knowledge (CCK) is the mathematical knowledge and skill possessed by teachers that are used for various situations or not specifically for teaching; (2) specialized content knowledge (SCK) is unique mathematical knowledge and skill used by teachers in their work, not commonly required for purposes other than teaching, and generally not owned by the teachers; (3) knowledge of the mathematical horizon (KMH) is knowledge of how mathematical topics related to the range of mathematics are included in the curriculum (Ball et al. 2008).

Many researchers show that conceptual knowledge is an important component in mathematics (Hiebert, 2005). Conceptual knowledge is knowledge that involves understanding of the relationship between concepts and principles including the schemes behind concepts (Hiebert et al., 2000). Conceptual knowledge is rich in relationships, and refers to the basic construction of mathematics and the relationship between ideas that describe mathematical procedures, and give meaning. In other words, conceptual knowledge is knowledge that binds the previously separate information into a relatively complete network. Thus, the unit of conceptual knowledge is not stored in isolated information but is part of a network.

Conceptual knowledge is knowledge that shows the interrelations between the basic elements in a larger structure and all of them functions together (Anderson et al. 2001). Conceptual knowledge consists of three types, namely category and classification, principle and generalization, as well as theory, model and structure. Category and classification are the basis for principle and generalization while principle and 
generalization are the basis for theory, model and structure. Based on the description, the research focuses on category and classification.

Category is a system that helps explore related topics while classification is a division according to certain classes. Classification is also a process of grouping objects based on similarity and difference. Furthermore, knowledge of category and classification includes: knowledge of category, class, section or structure that happens in a particular field of science (Anderson et al. 2001). Knowledge of category and classification is a very important knowledge because this knowledge also becomes the basis for teachers in classifying information and knowledge. Without the ability to do good categorization and classification, teachers will experience difficulties in learning.

In mathematics learning activities, in general mathematics deals with abstract ideas arranged hierarchically and structurally. Concepts in mathematics are built on the related underlying concepts. This condition implies that the teacher's conceptual knowledge of mathematical knowledge for teaching (MKT) becomes very important because conceptual knowledge is a bridge for teachers to understand and apply it in learning.

MKT-C is an integration or combination of MKT and conceptual knowledge possessed by teachers. In other words, MKT-C is the mathematics teacher's knowledge of material content for teaching which includes general material content, special material content and advanced mathematical material content related to category and classification.

\section{MKT-C Vignette Construction}

Regarding the definition in geometry, there are three categories of definition in geometry, namely: false definition, true definition, and economical definition (De Villiers, 2009). Definition is categorized false if it does not accurately state the nature (part or all) of the attributes or states the necessary conditions but does not state enough conditions. Definition is categorized true if it states necessary conditions and sufficient conditions. Definition is said to be economical if it states the necessary conditions and minimal sufficient conditions.

Furthermore, the definition structure is divided into partitional classification and hierarchical classification (De Villiers, 1994). Partitional classification is a classification that contains enough information to exclude non-examples. In other words, the partitional classification determines the quadrangle classification with one partition whereas hierarchical classification is a classification that contains all objects including all natures and is more economical than a partitional definition. In other words, hierarchical classification determines new classifications using classifications established before.

\section{MKT-C Vignette Development}

The development of vignette fulfills valid characteristics in terms of content, construct and language. According to Akker et al. (2006), the instrument developed is said to be good if it meets the criteria: valid, practical and effective. Valid relates to vignette which is developed based on strong theoretical rationales and internal consistency. Practical relates to the expert conclusion that the developed vignette can be applied and it is the 
fact that the vignette developed can be applied. Effective relates to vignette developed based on expert experience stating that operationally vignette gives results as expected.

In this study expert validation included content validation, construct and language. Practicality means that it can be applied to the teachers as planned and easy to use. Effective is seen from the achievement of teacher MKT-C.

\section{METHOD}

This research was carried out in January - May 2018. The method used in this study was a development research method. This development research was a type of research aimed at producing vignettes in measuring the math teacher MKT-C. This research was conducted in two phases, namely (1) preliminary phase: preparation and design and (2) formative evaluation phase: self-evaluation, prototyping (expert reviews, one-to-one and small group) and field test (Tessmer, 2013). Formative evaluation phase began with selfevaluation. The researcher evaluated his own on vignette that had been designed. The result of this self-evaluation was called draft vignette I. Furthermore, draft vignette I was given to expert reviews and one-to-one in parallel. The content, construct and language of Vignette would be reviewed by three validators in the field of mathematics education. Then it was revised and it produced draft vignette II. It was tried out to the math teachers in the small group of non-research subjects. They were asked for suggestions and comments for improvement. The revision was called draft vignette III. Figure 1 below illustrates the phases of the study.

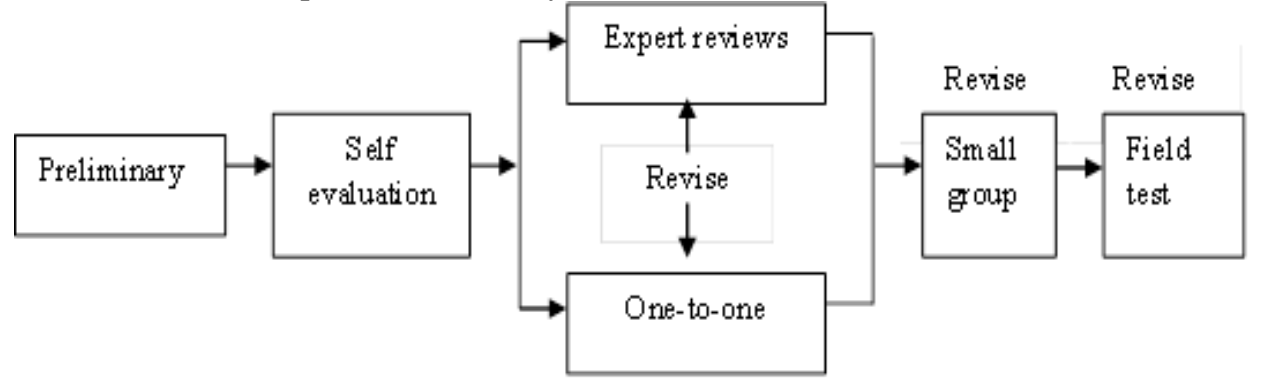

Figure 1

Image of Research Phases

Answers to vignette assignments were scored with criteria: score $3=$ economical definition or hierarchical-complete classification; score $2=$ true-not economical definition or hierarchical-incomplete classification; score $1=$ false definition or partitional classification, and score $0=$ no answer.

\section{FINDINGS}

\section{Preliminary}

At preparation phase, the researcher analyzed the material according to conceptual based MKT domains, namely: CCK-C, SCK-C and KMH-C. Table 1 shows the analysis of MKT-C material in the category and classification aspects. 
Table 1

MKT-C analysis in category and classification aspects

\begin{tabular}{lll}
\hline MKT-C & Aspect & Descriptor \\
\hline CCK-C & $\begin{array}{l}\text { Category of elements in } \\
\text { a quadrilaterals }\end{array}$ & $\begin{array}{l}\text { False (it is not appropriate to state the good nature of either a } \\
\text { part or all of the attributes or state the necessary conditions but } \\
\text { does not state the adequate conditions), True (it states the } \\
\text { necessary and sufficient conditions), Economical (it states the } \\
\text { necessary conditions and sufficient conditions with a minimum). }\end{array}$ \\
\cline { 2 - 4 } & $\begin{array}{l}\text { Classification of } \\
\text { elements in a } \\
\text { quadrilaterals }\end{array}$ & $\begin{array}{l}\text { Partitional (determines the classification of quadrilaterals with } \\
\text { one partition) or hierarchical (determines the new classification } \\
\text { using pre-established classifications) }\end{array}$ \\
\hline QCK-C & $\begin{array}{l}\text { Quadrilateral definition } \\
\text { category }\end{array}$ & $\begin{array}{l}\text { False (it is not appropriate to state the good nature of either a } \\
\text { part or all of the attributes or state the necessary conditions but } \\
\text { does not state the sufficient conditions), True (it states the } \\
\text { necessary and sufficient conditions), Economical (it states the } \\
\text { necessary conditions and sufficient conditions with a minimum). }\end{array}$ \\
& $\begin{array}{l}\text { Partitional (determines the classification of quadrilateral with } \\
\text { one partition) or hierarchical (determines a new classification } \\
\text { using pre-established classifications) }\end{array}$ \\
\cline { 2 - 4 } & $\begin{array}{l}\text { Quadrilaterals definition } \\
\text { classification }\end{array}$ & $\begin{array}{l}\text { False (it is not appropriate to state the good nature of either a } \\
\text { part or all of the attributes or state the necessary conditions but } \\
\text { does not state the sufficient conditions), True (it states the } \\
\text { necessary and sufficient conditions), Economical (it states the } \\
\text { necessary conditions and sufficient conditions with a minimum). }\end{array}$ \\
\hline KMH-C & $\begin{array}{l}\text { Quadrilateral type } \\
\text { category }\end{array}$ & $\begin{array}{l}\text { Partitional (determines the classification of quadrilateral with } \\
\text { one partition) or hierarchical (determines the new classification } \\
\text { using pre-established classifications) }\end{array}$ \\
& &
\end{tabular}

Then at the design phase, the researcher designed a research instrument in the form of a vignette which included writing indicators, looking for problems that matched the content and based on the vignette criteria. Table 2 shows the quadrangle MKT-C vignette indicator.

Table 2

Quadrilaterals MKT-C indicators

MKT-C Indicator

CCK-C a. Mentioning the elements in quadrilaterals.

b. Identifying the characteristics of parallelogram, rectangle, rhombus, square, trapezoid and kite.

c. Constructing the relationships of quadrilaterals elements

SCK-C a. Explaining the definition of quadrilaterals based on the knowledge.

b. Explaining the definition of parallelogram, rectangle, rhombus, square, trapezoid and kite based on the knowledge.

c. Constructing the relationships of quadrilaterals elements.

KMH-C a. Distinguishing quadrangle and not quadrilaterals.

b. Identifying convex quadrilaterals.

c. Identifying concave quadrilaterals.

d. Explaining the relationships of convex quadrilaterals and concave quadrilaterals.

e. Constructing the relationships of convex quadrilaterals and concave quadrilaterals.

Vignette was built into three tasks. The first task was CCK-C domain. The participants were given a description of the learning situation and asked to identify the characteristics of parallelogram, rectangle, rhombus, square, trapezoid and kite and 
construct from the quadrangle elements. The second task was SCK-C domain. The participants were asked to explain the definition of quadrangle, parallelogram, rectangle, rhombus, square, trapezoid and kite and construct the relationship of the quadrilaterals. The third task was KMH-C domain. The participants were asked to explain convex quadrilaterals and concave quadrilaterals and construct the relationship of both quadrilaterals. Table 3 shows the vignette of teacher MKT-C in quadrilaterals material.

Table 3

Vignette of teacher MKT-C in quadrilaterals

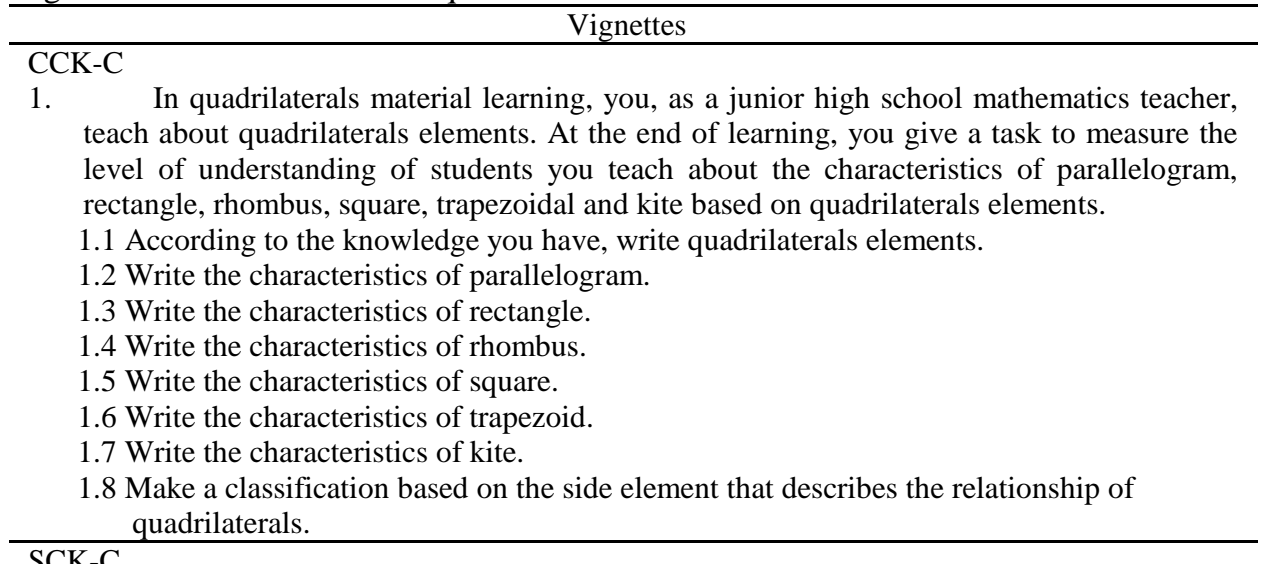

2. You are a junior high school mathematics teacher in Baubau City and will teach quadrilaterals. The quadrilaterals includes: parallelogram, rectangle, rhombus, square, trapezoid, and kite.

2.1 Write the definition of quadrilaterals according to your knowledge.

2.2 Write the definition of parallelogram

2.3 Write down the definition of rectangle

2.4 Write the definition of rhombus

2.5 Write the definition of square

2.6 Write the definition of trapezoid

2.7 Write the definition of kite.

2.8 Make a classification that describes the relationship among parallelogram, rectangle, rhombus, square, trapezoid, and kite in your opinion.

KMH-C

3. From the reference books, you can find geometric shapes as shown below.

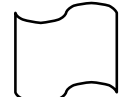

(A)

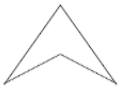

(B)

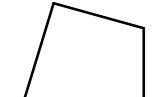

(C)<smiles>C1CC12CC2</smiles>

(D)

3.1 Check each picture above, which one is quadrilaterals? Give your reason. 3.2 Do you know convex quadrilaterals?

3.3 Do you know concave quadrilaterals?

3.4 Explain the difference between convex quadrilaterals and concave quadrilaterals! 3.5 Make a classification that describes quadrilaterals in general in your opinion!

International Journal of Instruction, July $2019 \bullet$ Vol.12, No.3 
Formative Evaluation

At preliminary phase, 21 items of vignette which were divided into CCK-C (8 items), SCK-C (8 items) and KMH-C (5 items) domains had been produced. Furthermore, the formative evaluation phase began with self-evaluation. The result of this vignette task was evaluated by the researcher called draft vignette I. Next, in the expert review, draft phase vignette I was validated in terms of content, construct and language by three experts in mathematics and mathematics education. Table 4 shows the results of the expert review.

Table 4

Expert validation result

\begin{tabular}{|c|c|c|c|c|}
\hline \multirow{2}{*}{ Validity } & \multirow{2}{*}{ Indicator } & \multicolumn{2}{|c|}{ Scoring scale } & \multirow[t]{2}{*}{ Comment } \\
\hline & & Yes & No & \\
\hline \multirow[t]{3}{*}{ Content } & $\begin{array}{l}\text { The vignette material is suitable for } \\
\text { teachers }\end{array}$ & $\sqrt{ }$ & & $\begin{array}{l}\text { Need to clarify what level } \\
\text { of mathematics teacher is } \\
\text { there? }\end{array}$ \\
\hline & $\begin{array}{l}\text { The vignette material is used to create } \\
\text { category and classification }\end{array}$ & $\sqrt{ }$ & & \\
\hline & $\begin{array}{l}\text { The vignette material encourages the } \\
\text { emergence of cognitive process }\end{array}$ & $\sqrt{ }$ & & \\
\hline \multirow[t]{4}{*}{ Construct } & $\begin{array}{l}\text { Sentences do not cause multiple } \\
\text { interpretations }\end{array}$ & & $\sqrt{ }$ & \\
\hline & $\begin{array}{l}\text { Vignette formulation uses question } \\
\text { sentences or commands }\end{array}$ & $\sqrt{ }$ & & \\
\hline & Vignette formulation is well structured & $\sqrt{ }$ & & \\
\hline & The given vignette limit is clear & $\sqrt{ }$ & & \\
\hline \multirow[t]{4}{*}{ Face } & $\begin{array}{l}\text { Vignette formulation uses the correct } \\
\text { mathematical sentence }\end{array}$ & $\sqrt{ }$ & & \\
\hline & $\begin{array}{l}\text { Vignette formulation uses good and } \\
\text { correct Indonesian language rules }\end{array}$ & $\sqrt{ }$ & & \\
\hline & $\begin{array}{l}\text { Vignette formulation uses words that are } \\
\text { known by the teacher }\end{array}$ & $\sqrt{ }$ & & $\begin{array}{l}\text { Convex and concave } \\
\text { terms need to be given an } \\
\text { explanation, do not let the } \\
\text { terms seem strange to the } \\
\text { teacher. }\end{array}$ \\
\hline & $\begin{array}{l}\text { The formulation of communicative } \\
\text { vignette }\end{array}$ & $\sqrt{ }$ & & \\
\hline
\end{tabular}

The vignette draft was also given one to one to two teachers. Teacher I: teaching at MTs Baubau, female, working period of 9 years, passed the certification in 2015. Teacher II: teaching at SMP 2 Lakudo, female, working period of 11 years and passed the certification in 2014. The revision result from one-to-one and expert review obtained draft vignette II.

The vignette collection in draft vignette II was tested in the small group. The small group consisted of 29 prospective mathematics teachers of teacher professional education in the position of FKIP Halu Oleo University Kendari in 2018. The teacher professional education program was a government program that aimed to prepare 
professional teachers for 1 year ( 2 semesters). The time provided for working on the vignette was 90 minutes individually. Subject characteristics: gender (male $=8$ and female $=21) ;$ age $(23-24=14$ people, $25-26=11$ people and $27-28=4$ people); academic background (mathematics $=4$ people and mathematics education $=25$ people).

After the small group stage was carried out, the draft vignette III was obtained then the validity and reliability were tested. Table 6 shows the distribution of CCK-C score

items. CCK- C items consisted of 8 items with $\sum X_{1}=578, \sum X_{1}^{2}=11688$.

Table 5

CCK-C score items distribution $(\mathrm{n}=29)$

\begin{tabular}{lllll}
\hline \multirow{2}{*}{$\operatorname{Item}\left(\mathrm{X}_{1}\right)$} & \multicolumn{5}{c}{ Score } \\
\cline { 2 - 5 } & 0 & 1 & 2 & 3 \\
\hline 1.1 & - & - & 22 & 7 \\
\hline 1.2 & - & - & 16 & 13 \\
\hline 1.3 & - & - & 10 & 19 \\
\hline 1.4 & - & - & 12 & 17 \\
\hline 1.5 & - & - & 8 & 21 \\
\hline 1.6 & - & - & 16 & 13 \\
\hline 1.7 & - & - & 12 & 17 \\
\hline 1.8 & 2 & 1 & 9 & 17 \\
\hline
\end{tabular}

Table 6 shows the distribution of SCK-C score items. SCK-C items consisted of 8 items with $\sum X_{2}=549, \sum X_{2}^{2}=10489$.

Table 6

Distribution of SCK-C score items $(\mathrm{n}=29)$

\begin{tabular}{lllll}
\hline \multirow{2}{*}{ Item $\left(\mathrm{X}_{2}\right)$} & \multicolumn{5}{c}{ Score } \\
\cline { 2 - 5 } & 0 & 1 & 2 & 3 \\
\hline 2.1 & - & - & 19 & 10 \\
\hline 2.2 & - & - & 24 & 5 \\
\hline 2.3 & - & - & 22 & 7 \\
\hline 2.4 & - & - & 18 & 11 \\
\hline 2.5 & - & - & 20 & 9 \\
\hline 2.6 & - & - & 11 & 18 \\
\hline 2.7 & - & - & 23 & 6 \\
\hline 2.8 & - & - & 10 & 19 \\
\hline
\end{tabular}

Table 7 shows the distribution of KMH-C score items. KMH-C items consisted of 8 items, with $\sum X_{\mathrm{a}}=180, \sum X_{\mathrm{a}}^{2}=1238$. 
Table 7

Score items distribution of KMH-C $(\mathrm{n}=29)$

\begin{tabular}{cllll}
\hline \multirow{2}{*}{ Item $\left(\mathrm{X}_{3}\right)$} & \multicolumn{5}{c}{ Score } \\
\cline { 2 - 5 } & 0 & 1 & 2 & 3 \\
\hline 3.1 & - & - & 27 & 2 \\
\hline 3.2 & 20 & - & 8 & 1 \\
\hline 3.3 & 20 & - & 8 & 1 \\
\hline 3.4 & 20 & - & 8 & 1 \\
\hline 3.5 & - & 8 & 14 & 7 \\
\hline
\end{tabular}

The results were analyzed using correlation product moment $\left(\mathrm{r}_{\mathrm{XY}}\right)$ from Karl Pearson and alpha Cronbach $\left(\alpha_{11}\right)$. The result showed that 21 items divided into 3 domains were valid with coefficient reliability, $\mathrm{CCK}-\mathrm{C}=0.607, \mathrm{SCK}-\mathrm{C}=0.508$ and $\mathrm{KMH}-\mathrm{C}=0.732$. Table 8 shows the result of validity and reliability of vignette CCK-C, SCK-C and $\mathrm{KMH}-\mathrm{C}$.

Table 8

Validity and reliability of vignette

\begin{tabular}{|c|c|c|c|c|}
\hline Vignette & Item & $r_{X Y}$ & $\mathrm{r}_{\text {table }}$ & Reliability \\
\hline \multirow{8}{*}{ CCK-C } & 1.1 & 0.40 & 0.355 & \multirow{8}{*}{0.607} \\
\hline & 1.2 & 0.67 & 0.355 & \\
\hline & 1.3 & 0.70 & 0.355 & \\
\hline & 1.4 & 0.81 & 0.355 & \\
\hline & 1.5 & 0.68 & 0.355 & \\
\hline & 1.6 & 0.37 & 0.355 & \\
\hline & 1.7 & 0.55 & 0.355 & \\
\hline & 1.8 & 0.48 & 0.355 & \\
\hline \multirow[t]{8}{*}{ SCK-C } & 2.1 & 0.51 & 0.355 & \multirow[t]{8}{*}{0.508} \\
\hline & 2.2 & 0.38 & 0.355 & \\
\hline & 2.3 & 0.51 & 0.355 & \\
\hline & 2.4 & 0.62 & 0.355 & \\
\hline & 2.5 & 0.60 & 0.355 & \\
\hline & 2.6 & 0.42 & 0.355 & \\
\hline & 2.7 & 0.55 & 0.355 & \\
\hline & 2.8 & 0.44 & 0.355 & \\
\hline \multirow[t]{5}{*}{ KMH-C } & 3.1 & 0.37 & 0.355 & \multirow[t]{5}{*}{0.732} \\
\hline & 3.2 & 0.94 & 0.355 & \\
\hline & 3.3 & 0.94 & 0.355 & \\
\hline & 3.4 & 0.94 & 0.355 & \\
\hline & 3.5 & 0.94 & 0.355 & \\
\hline
\end{tabular}

At field test phase, the researcher gave vignette to the research subjects. Vignette had 21 items and the time given for working was 90 minutes.

\section{DISCUSSION}

Vignette instrument developed to measure teacher MKT-C in this research was quadrilaterals material taught at junior high school. Vignette developed begun by 
analyzing the material and designing vignette as domains of CCK-C, SCK-C, and KMH$\mathrm{C}$ was called draft vignette I. To make it able to measure teacher MKT-C, internal and external validation on draft vignette I was done.

The internal validation process included aspects of content, construct and language involving 1 geometry expert and 2 mathematical education experts. Expert validation results indicated that vignette was worth using with revision. Improvements in content aspects included: in CCK-C vignette items, quadrilaterals natures were replaced with quadrilaterals characteristics; and quadrilaterals attributes were replaced with quadrilaterals elements; using operational verbs in cognitive process. The improvement of construct aspect included: each vignette question was specified one by one while improvements in language aspect included: $\mathrm{KMH}-\mathrm{C}$ vignette item was improved because it was not flexible. The researcher made improvements in vignette instrument and then the expert did the validation again. The result of expert validation was that draft vignette I was suitable for measuring MKT-C from the aspect of content, construct and language. This result is in line with the research of Maryono et al. (2016) showing that vignette is able to describe the pedagogical content knowledge (PCK) of mathematics teachers.

Then one-to-one was carried out by giving draft vignette I to two teachers to measure the level of readability of the instrument. The result of one-to-one was called draft vignette II. It showed a high level of readability.

The external validation process was given to all students of prospective teachers of teacher professional education. The prospective teachers were 29 people who had passed rigorous selection from several different universities. Descriptively, the items distribution of CCK-C and SCK-C subject showed a high level of achievement. The eight items of CCK-C and SCK-C were spread on score 2 (true-not economic definition or hierarchical-incomplete classification) and score 3 (economical definition or complete hierarchical classification). KMH-C subjects showed low performance, namely 3.2, 3.3, 3.4 and 3.5. Subjects generally had not understood convex quadrangle, concave quadrangle and made a relationship between them. It meant that concept or advanced mathematical knowledge related to the material being taught needed to be continuously developed by the teachers. For the item to distinguish quadrilaterals and not quadrilaterals, the subject showed high performance.

Validity test result showed that all vignette items were valid, including: 1.1, 1.2, 1.3, $1.4,1.5,1.6,1.7,1.8,2.1,2.2,2.3,2.4,2.5,2.6,2.7,2.8,3.1,3.2,3.3,3.4$ and 3.5 . It was because $r_{X Y}$ value is $>\left(r_{\text {table }}(29 ; \alpha=0.05)=0.355\right)$. It showed that a valid vignette could be used to measure the teacher MKT-C. The vignette reliability test result showed that vignette was reliable. The values were $\alpha_{11}(\mathrm{CCK}-\mathrm{C})=0.607, \alpha_{11}(\mathrm{SCK}-\mathrm{C})=0.508$, and $\alpha_{11}(\mathrm{KMH}-\mathrm{C})=0.732$. In other words, the vignette instrument had a level of accuracy and constancy. This finding is in line with the result of the study of Jeffries \& Maeder (2005) that measures the pedagogical understanding of teachers. It shows that vignette has a significant and predictive correlation for understanding teacher instructional strategies. 
Vignette can be used in the context of teacher content knowledge assessment because it is relatively easy to construct, provides useful focus and stimulus, and reflects real life (King et al., 2004).

\section{CONCLUSION}

The results of the present study showed that vignette can be used to develop mathematical knowledge to teach especially geometry. Validation results by experts on content, constructs and languages indicate that there is a slight revision of vignette. The readability test results on the teacher also meet the requirements. Results of analysis of validity and reliability in small-scale trials showed that vignette CCK-C, SCK-C and KMH-C (21 items) had valid and reliable values.

\section{Recommended Future Studies}

The researcher provides recommendations that can be used for further studies. Other research can be done by using cognitive process subindicators that are not directly related to MKT-C subdomains, such as, remember: subindicators recall; understand: the subindicators interpret, exemplify, classify, summarize, conclude, compare; apply executing subindicator; analyze subindicators organize, attribute; evaluate the subindicator criticizing; creating sub-indicators formulating, planning

\section{REFERENCES}

An, S., Kulm, G., \& Wu, Z. (2004). The pedagogical content knowledge of middle school, mathematics teacher in chine and the USA. Journal of Mathematics Teachers Education, 7, 145-172.

Anderson, L. W., Krathwohl, D. R., Airasian, P. W., Cruikshank, K. A., Mayer, R. E., Pintrich, P. R., \& Wittrock, M. C. (2001). A taxonomy for learning, teaching, and assessing: A revision of Bloom's taxonomy of educational objectives, abridged edition. White Plains, NY: Longman.

Ball, D. L., Thames, M., \& Phelps, G. (2008). Content knowledge for teaching: What makes it special? Journal of Teacher Education, 59(5), 389-407. https://doi.org/10.1177/0022487108324554

Ball, D. L., Lubienski, S., \& Mewborn, D. (2001). Research on teaching mathematics: The unsolved problem of teachers' mathematical knowledge. In V. Richardson (Ed.), Handbook of research on teaching (pp. 433-456). New York, NY: Macmillan.

Chick, H. L. (2003). Pre-service teachers' explanations of two mathematical concepts. In Proc. 2003 Annual conf. of the Australian Association for Research in Education.

De Villiers, M. (1994). The role and function of a hierarchical classification of quadrilaterals. For the Learning of Mathematics, 14(1), 11-18.

De Villiers, M. (2009). To teach definitions in geometry or teach to define. Colección Digital Eudoxus, 1(2), 1-18. $\quad$ Retrieved from http://www.cimm.ucr.ac.cr/ojs/index.php/eudoxus/article/viewFile/72/68. 
Fennema, E., \& Franke, M. L. (1992). Teachers' knowledge and its impact. In D. A. Grouws (Ed.), Handbook of research on mathematics teaching and learning (pp.147164). New York: Macmillan Publishing.

Hiebert, J., Stigler, J., Jacobs, J., Givvin, K., Garnier, H., Smith, M., Hollingsworth, H., Manaster, A., Wearne, D., \& Gallimore, R. (2005). Mathematics teaching in the United States today (and tomorrow): results from the TIMSS 1999 video study. Educational Evaluation and Policy Analysis, 27(2), 111-132.

Hiebert, J., Carpenter, T. P., Fennema, E., Fuson, K. C., Wearne, D., \& Murray, H., (2000). A Knowledge base for the Teaching Profession. What would it look like? Troy, NY: Heinemann.

Isiskal, M., \& Cakiroglu, E. (2011). The nature of prospective mathematics teachers' pedagogical content knowledge: The case of multiplication of fractions. Journal Math Teacher Education, 14(3), 213-230.

Jeffries, C., \& Maeder, D. W. (2005). Using vignettes to build and assess teacher understanding of instructional strategies. The Professional Educator, 27(1-2), 17-28.

Kim, Y. (2013). Teaching mathematical knowledge for teaching: Curriculum and challenges. (Unpublished doctoral dissertation). University of Michigan, Michigan.

King, G., Murray, C., Salomon, J. A., \& Tandon, A. (2004). Enhancing the validity and cross-cultural comparability of measurement in survey research. American Political Science Review, 98, 191-207.

Lappan, G. (2000). A vision of learning to teach for the 21st century. School Science and Mathematics, 100(6). 319-326.

Maryono, Sutawidjaja A., Subanji, \& Irawati, S., (2016). Portraying pedagogical content knowledge (PCK) of novice mathematics teachers using vignette. IOSR Journal of Research \& Method in Education, 6(4), 51-59.

Nolan, B., Dempsey, M., Lovatt, J., \& O’Shea, A. (2015) Developing Mathematical Knowledge for Teaching (MKT) for pre-service teachers: a study developing thinking in relation to the teaching of mathematics. Proceedings of the British for Research into Learning Mathematics 35(1), 54-59.

Poulou, M. (2001). The role of vignettes in the research of emotional and behavioral difficulties. Emotional and Behavioral Difficulties 6(1), 50-62.

Sahidin, L., Budiarto, M. T., \& Fuad, Y. (2019). Teacher's content knowledge in generalizing mind maps of quadrilateral. In Journal of Physics: Conference Series 1157(4), 1-7. IOP Publishing.

Tessmer, M. (2013). Planning and conducting formative evaluations: Improving the quality of education and training. London: Routledge. 
Thames, m. H. (2006). Using math to teach math: Mathematicians and educators investigate the mathematics needed for teaching (Critical Issues in Mathematics Education Series, Volume 2). Berkeley, CA: Mathematical Science Research Institute.

Türnüklü, E., \& Yesildere, S. (2007). The pedagogical content knowledge in mathematics: pre-service primary mathematics teachers' perspectives in Turkey. Issues in the Undergraduate Mathematics Preparation of School Teachers (IUMPS): The Journal, 1, 1-13.

Van den Akker, J., Gravemeijer, K., McKenney, S., \& Nieveen, N. (2006). Introducing to educational design research. In J. Van den Akker, K. Gravemeijer, S. McKenney, N. Nieveen (Ed.), Educational design research, (pp-1-8). London: Routledge. Retrieved from http://www.fi.uu.nl/publicaties/literatuur/EducationalDesignResearch.pdf.

Yeo, J. K. K. (2008). Teaching area and perimeter: Mathematics-pedagogical-content knowledge-in-action. In G. Merrilyn, B. Ray \& M. Katie (Ed.), Navigating currents and charting directions: Proceedings of the 31st annual Conference of the Mathematics Education Research Group of Australasia, University of Queensland, Brisbane 28th June-1st July 2008 (pp 621-627). Adelaide, S.A.: Mathematics Education Research Group of Australasia. 